\title{
KAJIAN KONDISI EMPIRIS DRAINASE KAWASAN PESISIR MENUJU SANITASI BERKELANJUTAN
}

\author{
Suning $^{1}$, Ela Rolita Arifianti ${ }^{2}$ \\ ${ }^{1}$ Dosen Perencanaan Wilayah dan Kota Fakultas Teknik Universitas PGRI Adi Buana Surabaya \\ ${ }^{2}$ Prodi Perencanaan Wilayah dan Kota Fakultas Teknik Universitas PGRI Adi Buana Surabaya \\ email : BrillyVan@gmail.com ${ }^{1}$, rolitaela@gmail.com²
}

\begin{abstract}
Abstrak
Pembangunan Drainase sesuai dengan standart SNI menjadi pedoman yang harus diikuti setiap pembangunan fisik dilakukan. Drainase merupakan komponen penting dalam perencanaan infrastruktur lingkungan bidang sanitasi. Tujuan penelitian ini adalah mengetahui kondisi empiris fisik drainase di kawasan pesisir khususnya di Kecamatan Sedati, dilihat dari segi kebersihan lingkungan dan mengevaluasi apakah drainase eksisting sudah sesuai dengan SNI 03-3424-1994 tentang Perencanaan drainase permukaan jalan. Metode penelitian yang digunakan deskriptif kualitatif dan kuantitatif. Teknik pengumpulan data dilakukan dengan sebar kuesioner dan wawancara, dengan teknik analisis evaluatif. Hasil penelitian menunjukkan bahwa 50\% terdapat ketidaksesuaian type bahan, bentuk dan jenis saluran serta adanya penampang drainase saluran sekunder yang rusak. Selain itu 35\% responden menyatakan sampah berserakan di drainase dan sekitarnya. Arahan drainase yang sesuai dengan SNI No. 03-3424-1994 di Kawasan Pesisir Sedati menuju sanitasi berkelanjutan adalah dilakukannya pengendalian bentuk dan tipe bahan saluran sekunder, rehabilitasi saluran secara berkala agar dapat memenuhi fungsi drainase untuk mengalirkan air, dan kegiatan normalisasi drainase secara kontinue.
\end{abstract}

Kata Kunci : Drainase Saluran Sekunder, Kawasan Pesisir Sedati, Normalisasi, Rehabilitasi, Sanitasi Berkelanjutan

\section{PENDAHULUAN}

Sejak tahun 1993 sampai dengan saat ini, dan banjir paling parah terjadi pada tahun 2014. Daerah yang terkena genangan banjir mencapai ketinggian $30 \mathrm{~cm}$ dengan lama genangan lebih dari 2 jam yaitu Kecamatan Waru, Gedangan, Taman, Krian, Buduran, Sukodono dan Sedati. Berita di koran Jawa Pos terbitan 19 Juni tahun 2014 menyebutkan bahwa penyebab utama banjir di wilayah tersebut adalah sistem drainase yang tidak memenuhi standart dan sistem drainase yang masih mempertahankan konsep konvensional. Kecamatan Sedati merupakan salah satu dari kecamatan yang berada di wilayah Kabupaten Sidoarjo yang memiliki ketinggian $4 \mathrm{mdpl}$. Drainase yang tidak memenuhi fungsi dan kualitas dapat menyebabkan kondisi lingkungan menjadi kumuh dan tercemar. Tujuan penelitian ini adalah mengetahui kondisi empiris fisik drainase di kawasan pesisir Kecamatan Sedati, dilihat dari segi kebersihan lingkungan dan mengevaluasi apakah drainase eksisting sudah sesuai dengan SNI 03-3424-1994 tentang Perencanaan drainase permukaan jalan.
Bagus, Ida (2011) meneliti tentang Managemen Resiko penanganan Banjir Pada Sistem Jaringan Drainase di Wilayah Kota Denpasar, hasil penelitian diperoleh sebanyak $20(68,96 \%)$ dari 29 resiko hasil identifikasi perencanaan drainase belum optimal dan masih tergolong sebagai resiko dominan. Sedangkan penelitian yang dilakukan oleh Damisi, M. Dhea (2014) menyimpulkan bahwa penyebab kekumuhan suatu lokasi dipengaruhi oleh kondisi penduduk dan sarana prasarana lingkungan kurang menunjang adanya bangunan yang belum sesuai dengan standart SNI salah satunya drainase.

\section{METODE}

2.1. Studi Literatur dan Pengambilan Data

Sekunder

Studi literatur yang dimaksud adalah melakukan kajian literatur terkait dengan peraturan, standart SNI pembangunan drainase, serta hasil-hasil penelitian yang sudah dilakukan oleh orang lain sebagai pembanding. 


\subsection{Pengambilan Data Primer}

Pengambilan data primer bertujuan untuk mengetahui secara eksisting kondisi empiris drainase di kawasan pesisir Sedati, dengan membandingkan apakah kondisi drainase sudah sesuai atau belum dengan peraturan SNI No.03-3424-1994 tentang perencanaan drainase permukaan jalan. Pengambilan data dilakukan dengan 185 responden di 5 desa pesisir yaitu desa Kalanganyar, Banjar Kemuning, Segoro Tambak, Gisik Cemandi dan Tambak Cemandi.

\subsection{Teknik Analisis Data}

Data sekunder yang diperoleh dijadikan sebagai data pendukung dan referensi untuk analisis deskriptif kualitatif dan kuantitatif. Data primer yang didapat digunakan untuk analisis evaluatif terkait kondisi drainase apakah sudah sesuai atau belum dengan peraturan SNI No.03-3424-1994 tentang perencanaan drainase permukaan jalan. Analisis evaluatif pada umumnya dilakukan untuk mengetahui hasil akhir dari sebuah program kebijakan, dalam rangka menentukan rekomendasi atas kebijakan yang lalu, dengan tujuan akhirnya adalah untuk menentukan kebijakan selanjutnya. McMillan dan Schumacher (2010) menjelaskan bahwa penelitian evaluatif merupakan salah satu penerapan dari penelitian yang digunakan untuk menentukan berhasil atau tidaknya atau apakah ada manfaat/nilai dari suatu program atau kebijakan. Secara keseluruhan metode penelitian ini ditunjukkan pada Gambar 1. Alur pikir penelitian.

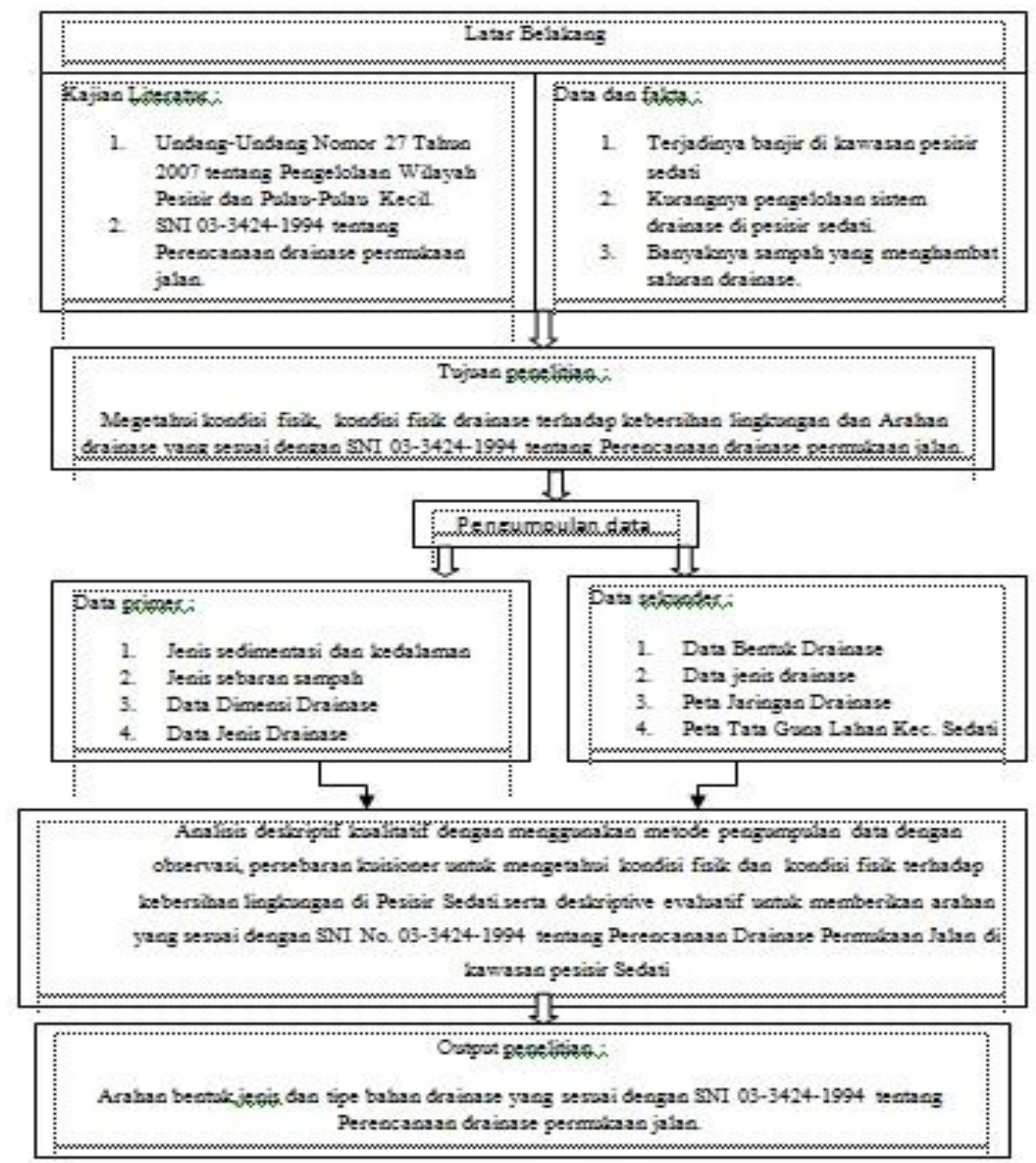

Gambar 1. Alur Pikir Penelitian

3. HASIL DAN PEMBAHASAN

3.1. Kondisi Fisik Drainase di kawasan pesisir Sedati.
Kecamatan sedati memiliki luas wilayah $79.430 \mathrm{~km}^{2}$. Kecamatan Sedati memiliki pola penggunaan lahan untuk pemukiman (12\%), 
kebun $(0,57 \%)$, industri $(0 \%)$, sawah $(5,4 \%)$, pekarangan $(0,78 \%)$ dan tambak $(50,73 \%)$. Wilayah objek penelitian ini meliputi desa yang berada di kawasan pesisir Kecamatan Sedati, yaitu: Desa Segoro Tambak, Desa Banjar Kemuning, Desa Gisik Cemandi, Desa Tambak Cemandi, dan Desa Kalanganyar. dengan batasbatas administrasi Kecamatan Sedati sebagai berikut :

$\begin{array}{ll}\text { Utara } & \text { : Kecamatan Waru } \\ \text { Timur } & : \text { Selat Madura } \\ \text { Selatan } & : \text { Kecamatan Buduran } \\ \text { Barat } & \text { : Kecamatan Gedangan }\end{array}$

Sistem drainase di kawasan pesisir menjadi sangat penting untuk dikaji karena memiliki karakteristik tersendiri dibandingkan dengan sistem drainase di kawasan non pesisir. Kawasan pesisir menjadi penting karena sebagian besar kota besar berada dikawasan pesisir, sekitar $60 \%$ dari populasi dunia berdiam di kawasan selebar $60 \mathrm{~km}$ dari pantai dan dapat diperkirakan akan naik menjadi $75 \%$ pada tahun 2025 . Keadaan topografi yang datar, terpengaruh oleh pasang surut yang masuk ke sungai atau saluran, dan kerap kali limpasan air hujan yang tidak bisa dialirkan secara gravitasi menuju ke suatu badan air (sungai, laut) membuat sistem drainase di kawasan pesisir mempunyai sistem penanganan yang khusus.

Kondisi empiris tersebut sesuai dengan hasil pernyataan Supirin (2004) bahwa pada sisi lain drainase merupakan prasarana umum yang sangat dibutuhkan oleh masyarakat untuk menuju kehidupan lingkungan yang aman, nyaman dan sehat. Hal ini menjadi penting untuk diperhatikan terutama drainase di permukaan jalan, karena drainase dapat berfungsi sebagai pembuangan kelebihan air yang tidak diinginkan pada suatu daerah, serta caracara penangggulangan akibat yang ditimbulkan oleh kelebihan air.

Hasil observasi dan kuesioner yang telah dilakukan, dimensi/bentuk, jenis dan tipe bahan dan sedimentasi yang ada di sistem drainase kawasan pesisir Sedati menunjukkan adanya penuh dengan endapan lumpur sehingga mengganggu lancarnya aliran drainase. Hal ini ditunjukkan 50\% terdapat ketidaksesuaian type bahan, bentuk dan jenis saluran serta adanya penampang drainase saluran sekunder yang rusak akibat tergerus aliran air. Sehingga perlu dilakukan rehabilitasi untuk menormalkan kembali fungsi drainase agar air dapat mengalir lancar sesuai dengan fungsinya.

Hasil penelitian ini juga didukung oleh Wismarini (2010) bahwa untuk mengatasi masalah banjir yang disebabkan oleh sistem drainase yang tidak sesuai, maka yang harus dilakukan adalah percepatan pengambilan keputusan penanggulangan banjir yang terprogram dan terencana. Rahmawati (2015) dalam penelitiannya juga menjelaskan bahwa terdapat 40 dari 131 saluran di perkotaan Sidoarjo yang tidak dapat menampung debit rencana, curah hujan rancangan adalah $94,511 \mathrm{~mm}$ periode ulang 10 tahun dan 83,9847 untuk periode ulang 5 tahun, sehingga yang dilakukan adalah menngunakan saluran porus atau dengan normalisasi saluran yang cocok untuk mengurangi limpasan dan resapan untuk air tanah.

Secara geografis kondisi eksisting kawasan pesisir Sedati ditunjukkan pada Gambar 2. Peta Administrasi dan Gambar 3. Peta jaringan drainase.

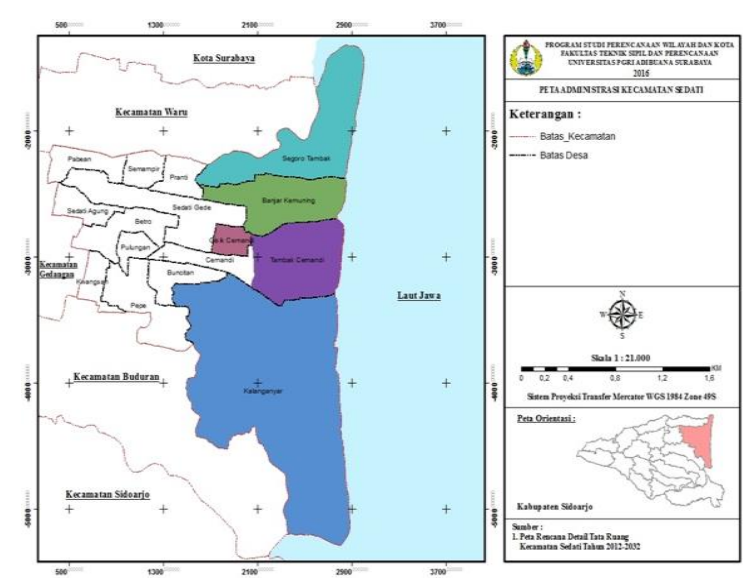

Gambar 2. Peta Administrasi Kawasan Pesisir Sedati 


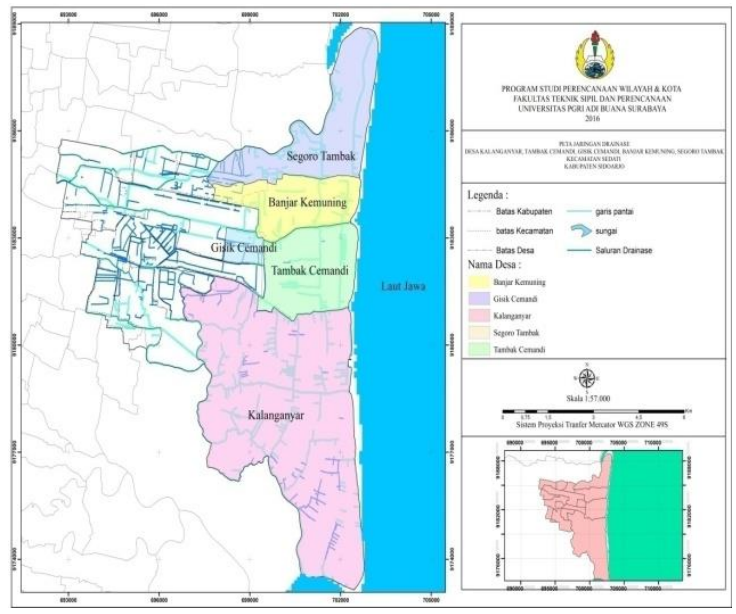

Gambar 3. Peta Jaringan Drainase

Gambar 3 di atas menunjukkan bentuk fisik jaringan drainase di Kawasan Pesisir yang terdapat di 5 desa pesisir. Desa Kalanganyar memiliki ketersediaan drainase yang memadahi sebesar $70 \%$, dengan dimensi dan bentuk drainase berbentuk Trapesium dan persegi dengan berbagai macam ukuran yaitu persegi dengan ukuran lebar $1 \mathrm{~m}$ dengan kedalaman $1 \mathrm{~m}$ dan trapesium dengan ukuran lebar $2 \mathrm{~m}$ dan kedalaman $1 \mathrm{~m}$. Drainase yang ada memiliki 4 jenis yaitu Trapesium tanpa tutup, Trapesium Tertutup, Persegi tanpa Tutup dan Persegi dengan mengunakan tutup.

Desa Tambak Cemandi memiliki ketersediaan drainase atau saluran air yang memadahi karena $97 \%$ responden menyatakan tersedia jaringan drainase dan 3\% menyatakan tidak teresdia drainase. Bentuk drainase yang ada rata-rata berbentuk persegi empat dengan jenis drainase terbuka dan tertutup. Drainase berbentuk persegi empat menggunakan tutup memiliki Lebar $60 \mathrm{~cm}$ dan kedalaman $50 \mathrm{~cm}$, drainase berbentuk persegi empat terbuka memiliki lebar $40 \mathrm{~cm}$ dan kedalaman $50 \mathrm{~cm}$. Tipe bahan yang digunakan pada drainase yang berbentuk persegi empat tanpa tutup adalah batu bata yang dilapisi dengan lapisan semen. Bentuk saluran persegi empat dengan jenis tertutup meggunakan jenis bahan beton bertulang dengan tutup plat beton bertulang.

Drainase di desa Gisik Cemandi memiliki 2 bentuk saluran yaitu trapesium dan persegi empat dengan 3 jenis drainase yaitu trapesium terbuka, persegi empat terbuka dan persegi empat tertutup. Jenis drainase yang berbentuk trapesium terbuka memilki lebar 1,5 $\mathrm{m}$ dengan kedalaman $1 \mathrm{~m}$, persegi empat terbuka memiliki lebar $40 \mathrm{~cm}$ dengan kedalaman $60 \mathrm{~cm}$ dan persegi empat tertutup memiliki lebar $35 \mathrm{~cm}$ dengan kedalaman $30 \mathrm{~cm}$. Drainase di desa Gisik Cemandi dengan bentuk trapesium memiliki tipe bahan yang terbuat dari batu kali, persegi empat terbuka memiliki tipe bahan yang terbuat dari batu bata yang dilapisi semen dan bentuk persegi empat tertutup memiliki tipe bahan batu bata yang dilapisi semen dengan tutup cor yang terbuat dari pasir dan semen.

Di desa Banjar Kemuning 10\% masyarakat menyatakan tersedia saluran drainase, $86 \%$ mengatakan tidak tersedia jaringan drainase dan $4 \%$ tidak tau. Desa Banjar Kemuning memiliki drainase yang berbeda dimensi antara satu dengan yang lainnya sesuai dengan besar aliran airnya. Dimensi atau bentuk drainase yang ada rata-rata berbentuk persegi empat dengan jenis drainase terbuka dan tertutup. Drainase berbentuk persegi empat menggunakan tutup memiliki Lebar $35 \mathrm{~cm}$ dan kedalaman $30 \mathrm{~cm}$, drainase berbentuk persegi empat terbuka memiliki lebar $40 \mathrm{~cm}$ dan kedalaman $20 \mathrm{~cm}$. Tipe bahan yang digunakan pada drainase yang berbentuk persegi empat tanpa tutup adalah batu bata yang dilapisi dengan lapisan semen dan bentuk saluran persegi empat dengan jenis tertutup meggunakan jenis bahan batu bata dengan lapisan semen dan menggunakan tutup yang berbahan cor yaitu pasir dan semen.

Di desa Segoro Tambak $80 \%$ responden mengatakan tersedia drainase, $10 \%$ menyatakan tidak tersedia drainase dan $5 \%$ orang responden berpendapat tidak tau dan 5\% berkata lainnya. Segoro Tambak memiliki ketersediaan drainase atau saluran air yang memadahi dengan dimensi yang berbeda antara satu dengan yang lainnya sesuai dengan besar aliran airnya yang keseluruhan airnya mengalir ke sebuah sungai yang berada di sebelah utara desa Segoro tambak. Saluran drainase yang mendominasi di desa Segoro Tambak adalah saluran drainase berbentuk persegi empat tertutup. Drainase berbentuk persegi empat tertutup memiliki ukuran yang berbeda antara lain Lebar $30 \mathrm{~cm}$ dengan kedalaman $40 \mathrm{~cm}$ dan lebar 40 dengan kedalaman $50 \mathrm{~cm}$. Tipe bahan yang digunakan adalah beton bertulang dengan tutup yang berbahan dari plat beton bertulang serta ada juga yang berbahan dari batu bata yang dilapisi semen dengan menggunakan tutup cor dari pasir dan semen.

3.2. Kondisi Fisik kebersihan lingkungan di sekitar drainase. 
Secara umum permasalahan kondisi eksisting drainase dan persampahan di masingmasing desa di kawasan pesisir Sedati hampir sama. Kondisi fisik kebersihan lingkungan di sekitar drainase sesuai $35 \%$ responden menyatakan sampah berserakan di sekitar dan di dalam saluran drainase di keseluruhan desa Pesisir. Sampah yang berserakan di sekitar drainase antara lain sampah hasil rumah tangga dan sedimen yang menebal di dasar saluran drainase. Hal ini dapat dilihat pada Gambar 4, 5, 6, 7 dan 8 Peta mapping saluran drainase masing-masing desa pesisir.

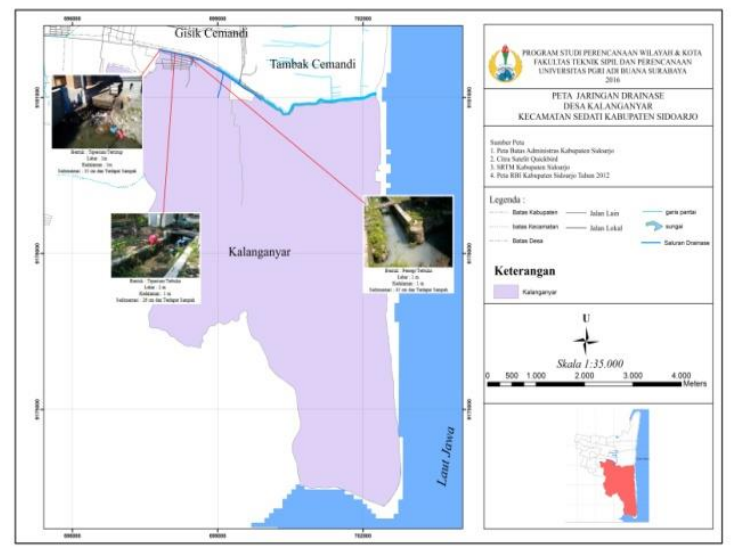

Gambar 4. Peta Mapping drainase desa Kalanganyar

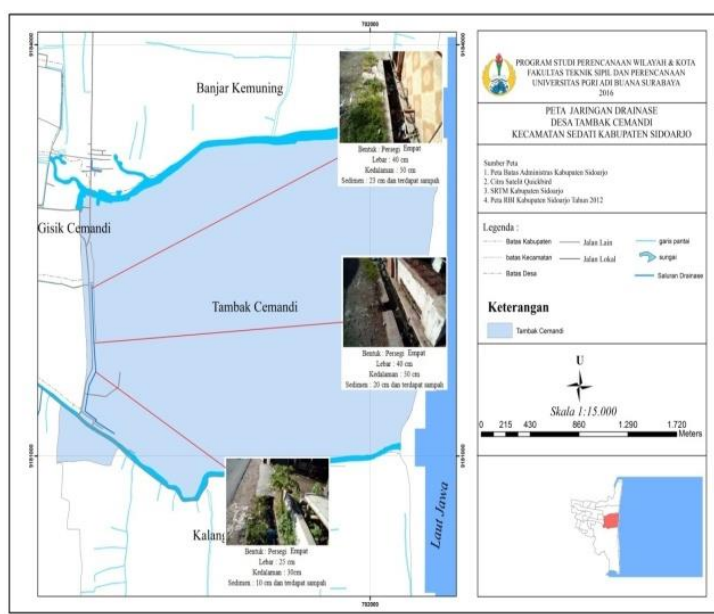

Gambar 5. Peta Mapping drainase di desa Tambak Cemandi

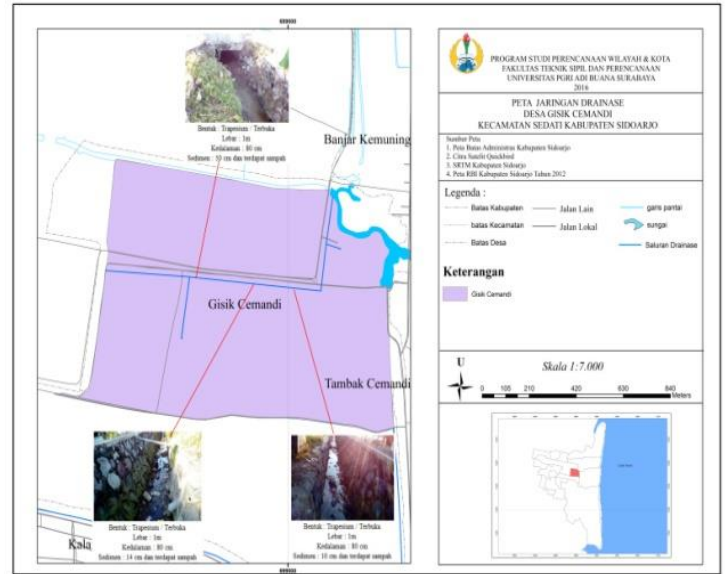

Gambar 6. Peta Mapping drainase di desa Gisik Cemandi

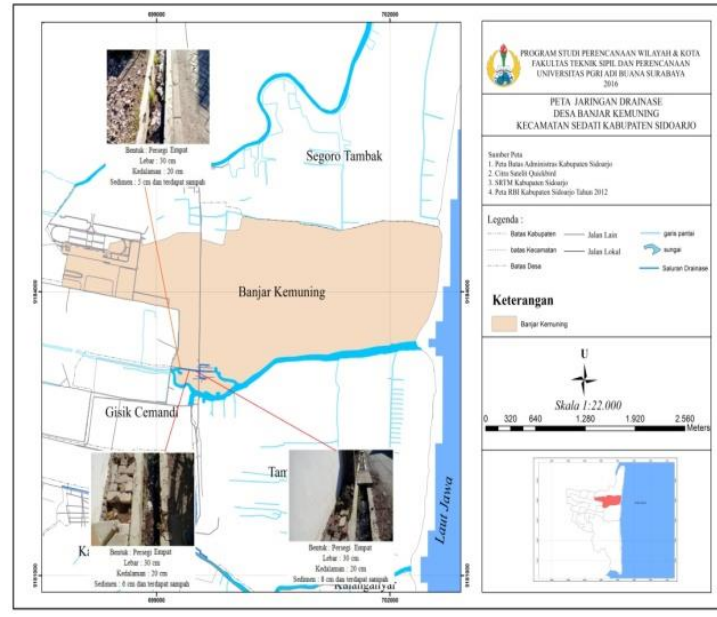

Gambar 7. Peta Mapping drainase di desa Banjar Kemuning

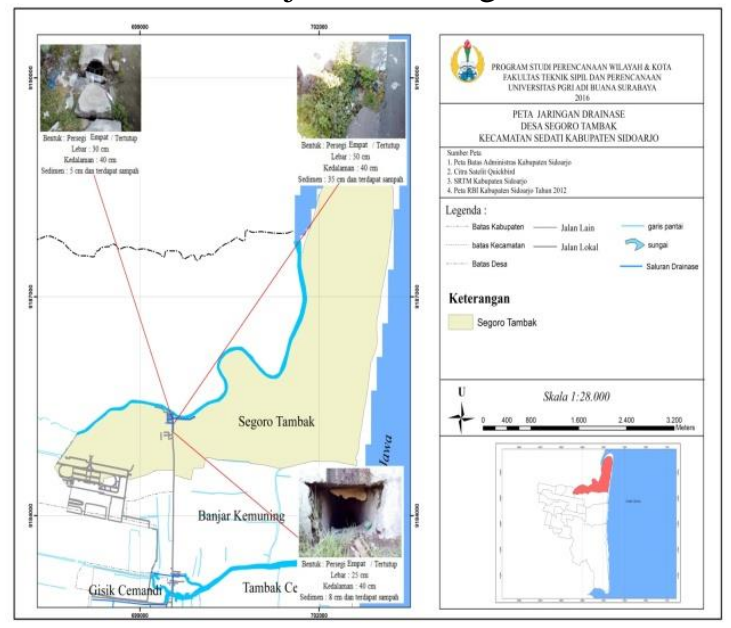

Gambar 8. Peta Mapping drainase di desa Segoro Tambak

Masing-masing Gambar di atas dapat diuraikan bahwa kondisi persampahan di desa Kalanganyar $15 \%$ masyarakat menyatakan sampah berserakan, $40 \%$ tidak ada tempat sampah, 25\% masyarakat membuang sampah di sembarang tempat dan $20 \%$ menjawab yang 
lainnya. Desa Tambak Cemandi 38\% masyarakat menyatakan sampah berserakan, $44 \%$ tidak ada tempat sampah, $18 \%$ masyarakat membuang sampah di sembarang tempat. Desa Gisik Cemandi 26\% masyarakat menyatakan sampah berserakan, $50 \%$ tidak ada tempat sampah, $24 \%$ masyarakat membuang sampah di sembarang tempat. Desa Banjar Kemuning $17 \%$ masyarakat menyatakan sampah berserakan, $42 \%$ tidak ada tempat sampah, $41 \%$ masyarakat membuang sampah di sembarang tempat. Desa Segoro Tambak 26\% masyarakat menyatakan sampah berserakan, 59\% tidak ada tempat sampah, $15 \%$ masyarakat membuang sampah di sembarang tempat. Melihat permasalahn kondisi eksisting drainase di kawasan pesisir Sedati tersebut, maka perlu adanya partisipasi masyarakat dan pemerintah dalam melakukan normalisasi saluran drainase dengan cara pengerukan sampah dan sedimen pada saluran drinase secara berkala. Hal ini untuk mengurangi volume sampah dan sedimen yang mengganggu aliran air.

\subsection{Arahan Drainase Yang Sesuai Dengan Standart SNI}

Peraturan SNI No. 03-3424-1994 digunakan sebagai acuan untuk merencanakan struktur drainase permukaan jalan yang bertujuan untuk mendapatkan keseragaman dalam cara merencanakan drainase permukaan jalan yang sesuai dengan perencanaan teknis. Berdasarkan hasil observasi lapangan dan penyebaran kuisioner dengan responden sebanyak 185, secara umum kondisi fisik drainase di masing-masing desa di kawasan pesisir Sedati memiliki permasalahan drainase yang hampir sama. Cara menentukan arahan adalah dengan membandingkan kondisi eksisting dengan peraturan SNI No.03-34241994 sehingga drainase yang ada sesuai dengan peraturan SNI No. 03-3424-1994 tantang perencanaan drainase permukaan jalan. Hasil analisis menunjukkan bahwa arahan drainase untuk Kawasan Pesisir Sedati dengan melakukan pengendalian bentuk dan tipe bahan saluran sekunder atau menyesuaikan bentuk dan jenis bahan drainase sesuai dengan SNI, dan harus dilakukan rehabilitasi saluran secara berkala agar dapat memenuhi fungsi drainase untuk mengalirkan air.

\section{KESIMPULAN}

1. Kondisi eksisting fisik drainase di Kawasan Pesisir Sedati masing-masing desa menunjukkan bentuk saluran drainase sekunder yang berbeda, baik dalam bentuk trapesium dan persegi dengan type terbuka dan tertutup serta dengan berbagai macam bahan antara lain batu kali, plester dan beton bertulang. 50\% kondisi drainase memiliki kekurangan terhadap kesesuaian drainase antara lain type bahan, bentuk saluran serta kondisi drainase yang rusak akibat tergerus aliran air.

2. Kondisi fisik saluran drainase dilihat dari segi kebersihan lingkungan menunjukkqn 35\% sampah berserakan di sekitar saluran dan di dalam saluran drainase. Sehingga keberadaan sampah dapat mengganggu kondisi fisik dan kebersihan lingkungan.

3. Arahan drainase yang sesuai dengan SNI No. 03-3424-1994 tentang Drainase Permukaan Jalan khususnya di Kawasan Pesisir Sedati adalah dengan melakukan kegiatan mempertahankan bentuk saluran drainase yang sudah ada, rehabilitasi saluran drainase yang belum memiliki kesesuaian standart, normalisasi penampang drainase yang rusak akibat tergerus aliran sungai, optimalisasi kegiatan sedimentasi dan persampahan, serta dengan melakukan pengerukan secara berkala.

\section{UCAPAN TERIMA KASIH}

Terima kasih kepada saudari Ela Rolita Arifianti yang telah menjadi mitra penelitian, sehingga penelitian ini dapat diselesaikan dengan baik. Terimakasih juga kami ucapkan kepada Kampus Universitas PGRI Adi Buana Surabaya yang telah mendukung terlaksananya penelitian ini.

\section{DAFTAR PUSTAKA}

Bagus, Ida. 2011. Manajemen Resiko Penanganan Banjir Pada Sistem Jaringan Drainase d Wilayah Kota Depassar. Universitas Udayana Bali

Damisi, M. Dhea. 2014. Analisis Faktor-Faktor Kwasan Permukiman Pesisir Tradisional. Uiversitas Sam Ratulangi. McMillan JH dan Schumacer, S. 2010. Research In Education : Evidence Based Inquiry. New Jersey : Pearson Education Inc. 
Rahmawati, Anita. 2015. Evaluasi Sistem Drainase Terhadap Penanggulangan Genangan di Kota Sidoarjo.

Suripin. 2004. Sistem Drainase Yang Berkelanjutan. Penerbit Andi Offset, Yogyakarta.

SNI No. 03-3424-1994 Perencanaan Drainase Permukaan Jalan

Undang-Undang No. 27 tahun 2007 tentang pengelolaan wilayah pesisir dan pulau pulau kecil

Wismarini, Dwiyati. 2010. Analisis Sistem Drainase Kota Semarang Berbasis Sistem Informasi Geografi dalam Membantu Pengambilan Keputusan bagi Penanganan Banjir. Universitas Stikubank.Semarang.

RTRW Kabupaten Sidoarjo Tahun 20092029. Laporan

Kecamatan Sedati Dalam Angka 2015. Laporan 